\section{Respiratory Metabolism of Parasitic Helminths without Participation of the Cytochrome System}

LASER $^{1}$ has demonstrated high succinic dehydrogenase activity in extracts of muscle pulp of Ascaris lumbricoides. In the presence of succinate these preparations reduce methylene blue, but do not react with atmospheric oxygen. On the other hand, succinate stimulates the respiration of dialysed muscle mince of $A$ scaris ${ }^{2}$. Furthermore, we have observed that homogenates of thoroughly washed Ascaris muscle oxidize succinate even in the absence of methylene blue. The activity of this preparation was markedly higher in 100 per cent oxygen than in air, and was increased when catalase and ethyl alcohol were added, indicating the production of hydrogen peroxide ${ }^{1}$. No oxygen uptake was observed under similar conditions in the absence of succinate. Therefore, succinic dehydrogenase of Ascaris muscle can transfer hydrogen either to methylene blue or to an enzyme system, which, in turn, reacts with atmospheric oxygen. However, the latter is not identical with the cytochrome-cytochrome oxidase system considered to be the universal catalyst of all respiring cells ${ }^{3}$

Addition of homogenates of unwashed Ascaris muscle did not increase the oxidation of succinate by succinoxidase of pig heart prepared according to Keilin and Hartree ${ }^{4}$. This preparation is deficient in cytochrome $c$, and as little as $3 \times 10^{-10}$ moles of cytochrome $c$ can be determined manometrically by this assay ( $\left.v_{F}, 1.0 \mathrm{ml} . ; v_{G}, 4-5 \mathrm{ml} . ; p \mathrm{H} \mathrm{7.4}\right)$. The activity of pig heart succinoxidase in the presence of succinate and of low concentrations of cytochrome $c$ $\left(6 \times 10^{-7}\right.$ molar) was not inhibited by the same homogenate of Ascaris muscle. On the basis of this assay, Ascaris muscle contains less than $2 \times 10^{-9}$ moles of cytochrome $c$ per gm. Furthermore, no cytochrome oxidase activity could be detected in Ascaris muscle homogenates when they were added to cytochrome $c$ (molar concentration : $3.8 \times 10^{-5}$ ) and hydroquinone (molar concentration: $\left.3.6 \times 10^{-2}\right)\left(15^{\circ} \mathrm{C}\right.$. ; $\left.p \mathrm{H} 7 \cdot 1\right)$. By contrast, cytochrome oxidase activity was observed when homogenates of rat lung were used. The latter contained five times less tissue than the Ascaris homogenates. Among mammalian tissues, lung has the lowest cytochrome oxidase activity ${ }^{5}$. The absence of cytochrome oxidase activity was not due to an inhibitory effect of this tissue on the enzyme, because the activities of cytochrome oxidase preparations $s^{4,6}$ were the same in the presence or in the absence of Ascaris muscle homogenates.

While succinate oxidation by washed Ascaris muscle preparations was increased by methylene blue (but not by two metalloporphyrin pigments recently isolated from Ascaris by Davenport?), no effect was observed with either cytochrome $c$ or a cytochrome oxidase preparation containing no succinic dehydrogenase ${ }^{\theta}$, added alone or together. Therefore, succinic dehydrogenase of Ascaris does not react with the cytochrome system, the presence of which we were unable to detect in this organism. Possibly a flavine enzyme participates in the oxidation of succinate by Ascaris muscle.

Evidence has been obtained that the cytochrome system is not involved in the respiration of two other parasitic worms, the filarial nematode Litomosoides carinii and the trematode Schistosoma mansoni. The oxygen uptake of these two helminths is inhibited completely by cyanide (molar concentration : $\left.2 \times 10^{-4}\right)^{8}$.
Yet, assay procedures similar to those used for Ascaris muscle revealed no cytochrome $c$ nor cytochrome oxidase activities in the filariæ. The schistosomes contained measurable cytochrome and cytochrome oxidase activities; but they accounted for less than 10 per cent of the overall oxygen consumption of these worms.

It is concluded that respiration in the above three helminths is mediated predominantly, if not exclusively, by respiratory catalysts which are not identical with the cytochrome system.

We are indebted to the Division of Research Grants and fellowships of the National Institutes of Health, U.S. Public Health Service, for a grant in support of this work.

\section{E. Buedine}

Department of Pharmacology,

B. Charms

Western Reserve University, School of Medicine,

Cleveland, Ohio. Sept. 14.

${ }^{1}$ Laser, H., Biochem. J., 38, 333 (1944) 'Van Grembergen, G., Van Damme, R., and Vercruysse, R., Enzymo-
logia, 13, $325(1949-50)$.

${ }^{3}$ Keilin, D., and Wang, Y. L., Biochem. J., 40, 855 (1946).

${ }^{4}$ Keilin, D., and Hartree, E. F., Proc. Roy. Soc., B, 125, 171 (1938).

${ }^{5}$ Stotz. E., J. Biol. Chem., 131, 555 (1939).

B Haas, E., J. Biol. Chem., 148, 481 (1943).

? Davenport, H. E., Proc. Roy. Soc., B, 136, 255 (1949-50).

${ }^{8}$ Bueding, E.. J. Exp. Med., 89, 107 (1949). Ross, O. A., and Bueding, (unpublished work).

\section{Influence of Folic Acid on Xanthine Oxidation in vitro}

AN inverse relationship between liver xanthine oxidase and dietary folic acid has been demonstrated in the chick $^{\mathbf{1}, 2}$. Similar effects are reported for $\mathrm{D}$-amino-acid oxidase activity ${ }^{2,3}$ and in glycine metabolism $^{4}$. Since hydrogen peroxide, a product resulting from oxidations involving flavo-protein enzymes, is known to bring about destruction of hæmoglobin ${ }^{5}$, these observations have been interpreted to mean that an excessively rapid rate of such oxidations may contribute to the breakdown of hæmoglobin or hæm-containing enzymes in vivo and thus explain a biochemical change in folic acid deficiency ${ }^{1}$. However, recent reports would suggest that folic acid may not have a direct influence on catalase activity ${ }^{2}$ or on liver xanthine oxidase in the $\mathrm{rat}^{6}$. Furthermore, earlier observations on the in vitro inhibition by folic acid of xanthopterin oxidase activity have now been ascribed to an aldehyde impurity which is a primary photo-fission product of the vitamin?

The influence of folic acid on xanthine oxidation seemed therefore to merit re-investigation. Working with systems containing a milk xanthine oxidase preparation and catalase ${ }^{8}$, we have observed in various experiments some 10-40 per cent stimulation of xanthine oxidation in vitro in presence of aldehydefree folic acid in concentrations of 60-300 migm. per cent, which correspond more nearly to the levels obtaining in normal plasma and liver than those used by previous workers. Folic acid does not exert any activation in absence of catalase, the influence of which was shown to be enzymic from experiments with heated catalase. In amounts of $1.5 \mathrm{gm}$. and more, folic acid inhibits xanthine oxidase activity by at least 20 per cent, presumably by competition with 